shortly after an $\mathrm{N}$ trial converts the $\mathrm{N}$ trial to an $\mathbf{R}$ trial (mechanism unspecified, Surridge \& Amsel, 1966) or converts $\mathrm{N}$ to $\mathbf{R}$ by interfering with the consolidation of the frustration reaction (Lobb \& Runcie, 1967). The important point for our purposes is that both hypotheses assume that the effectiveness of ITR will decrease as the time between nonreward and ITR increases. Our results, of course, show just the opposite effect. The effectiveness of ITR increased with increasing time between nonreward and ITR. Surridge \& Amsel (1966) also suggest that ITR effects may be due, in part, to a design artifact. They point to the fact that some ITR studies include a PR control group that receives ITR following $R$ trials. They assume that this procedure increased the reward magnitude of $\mathbf{R}$ trials, and that ITR effects may be due to an increase in resistance to extinction for the PR control rather than to (or in addition to) whatever decremental effects are caused by ITR following $\mathrm{N}$ trials. This hypothesis cannot account for the present results since our PR control did not include ITR.

Only one hypothesis that might account for the effectiveness of ITR at PR-30 and the failure of ITR at PR-15 has occurred to the present authors. It will be recalled that these two groups differed not only in the waiting period following the $\mathrm{N}$ trial and preceding ITR, but they also varied in the time following ITR and the start of $R$ trials (15 sec wait for PR-15 and immediate in PR-30). This latter interval may have facilitated a discrimination between $R$ and ITR trials in the PR-15 group. These Ss received ITRs that were "set off" from $N$ or R trials by a $15-\mathrm{sec}$ interval both before and after the ITR placement. The PR-30 Ss were placed in the startbox for $R$ trials immediately after ITR placement (this has been the common procedure in successful ITR studies). Perhaps an increased discriminability between $R$ and ITR trials in PR-15 Ss caused the decrease in the effectiveness of ITR. A similar discrimination hypothesis has been suggested by Capaldi \& Oliver (1967) in accounting for the decreased effectiveness of ITR following its repeated use.

\section{REFERENCES}

CAPALDI, E. J. A sequential hypothesis of instrumental learning. In K.W. Spence and J.T. Spence (Eds.), The psychology of learning and motivation: Advances in research and theory. New York: Academic Press, 1967. Pp. 67-156.

CAPALDI, E. J., HART, D., \& STANLEY, L. R. Effect of intertrial reinforcement on the aftereffect of nonreinforcement and resistance to extinction. Journal of Experimental Psychology, 1963, 65, 70-74.

CAPALDI, E. J., \& OLIVER, W. P. Effect of intertrial reinforcement following a substantial number of consistently rewarded trials. Journal of Experimental Psychology, 1967 $75,135-138$.

CAPALDI, E. J., \& POYNOR, H. Aftereffects and delay of reward. Journal of Experimental Psychology, 1966, 71, 80-88.

LOBB, H., \& RUNCIE, D. Intertrial reinforcement as interference with consolidation. Psychonomic Science, 1967, 9, 25-26.

RENNER, K. E. Delay of reinforcement: A historical review. Psychological Bulletin, 1964, 61, 341-361.

SURRIDGE, C. T., \& AMSEL, A. Acquisition and extinction under single alternation and random partial-reinforcement conditions with a 24-hour intertrial interval. Journal of Experimental Psychology, 1966, 72, 361-368. NOTE

1. This research was partially supported by Grant No. 8469 from the National Science Foundation to Southern Methodist University. The study was conducted according to the APA statement of "Principles for the care and use of animals," June 26, 1968. Reprints may be obtained from Patrick E. Campbell, Department of Psychology, Southern Methodist University, Dallas, Tex. 75222.

\title{
Suppressing an avoidance response by a pre-aversive stimulus ${ }^{1}$
}

H. M. B. HURWITZ and A. E. ROBERTS, University of Tennessee, Knoxville, Tenn. 37916

Subjects trained under a free operant-avoidance schedule were exposed to a 1-min clicker (CS) followed by an unavoidable shock (US). During the preaversive stimulus, overall response rates declined and frequency of shock increased. During this period, the response-frequency distribution was U-shaped. When the US was removed, response rates increased and shock rates decreased.

Hurwitz \& Black (1968) reported that when a signaled shock was superimposed on responding maintained by a free-operant-avoidance schedule (FOA) (Sidman, 1953), response rates during the signal (CS) were often only marginally affected (when compared to nonsignaled response rates). On the other hand, shock rates during CS increased dramatically, compared to shock rates during nonsignaled periods. It should be noted that under the FOA schedule increases in shock rates during CS can only result from reduced responding, so that the distribution of responses during CS must be different from response distributions during nonsignaled periods.

The purpose of this study was to investigate the distribution of avoidance responses during periods prior to the signal (pre-CS), during the pre-aversive signal (CS), and following termination of the signal (post-CS).

\section{SUBJECTS}

Three female hooded rats, who were experimentally naive, were employed as Ss. PROCEDURE

An FOA schedule was programmed so that $0.1-\mathrm{sec}$ shocks of $0.8 \mathrm{~mA}$ were given at 5 -sec intervals unless a lever press occurred, in which case shock was postponed for $20 \mathrm{sec}$. Houselights were turned on at the beginning of the session and, coincident with a lever press, were momentarily extinguished.

After 39 daily 2-h training sessions under a free-operant-avoidance schedule, a signal (CS), followed within $60 \mathrm{sec}$ by a shock (US), was superimposed on FOA responding. The CS-US was presented on a variable-interval schedule, with a mean rate of $4 \mathrm{~min}$. Shock was the same intensity as that used under the FOA procedure. Thirty CS-US pairings were presented on each session.

After 20 sessions in which the CS-US was given, the experimental conditions were changed, and the CS was presented alone without being followed by US. Ten sessions were given under this extinction procedure.

\section{RESPONSE MEASURES}

The effects of the CS-US procedure were investigated in terms of number of FOA shocks occurring in signaled and nonsignaled periods of the session. A distribution of responding was obtained in the following manner: The 60-sec pre-CS, $\mathrm{CS}$, and post-CS periods were divided into five 12-sec intervals; responses occurring during each interval were separately recorded. 


\section{RESULTS}

Figure 1 presents mean response rates for the following experimental periods: Panel A, the first 10 CS-US sessions; Panel B, the final 10 CS-US sessions; and Panel C, the last 8 sessions in which CS was presented alone.

Panel A presents mean response rates for each interval of the pre-CS, CS, and post-CS periods for each $S$ during the first 10 CS-US sessions. Point $T$ presents the mean response rate observed for each $S$ during the last 10 FOA training sessions. The introduction of the CS-US procedure resulted in reduced pre-CS responding for one S (S2). Pre-CS responding was generally stable for all Ss. The onset of CS resulted in a temporary increase in responding for two of three Ss, immediately followed by reduced responding for all Ss; toward the end of the CS period, responding again increased. Response distributions during the CS periods indicated a U-shaped function over time. Compared to both pre-CS and CS periods, enhanced response rates occurred during early post-CS intervals, followed by a gradual reduction in responding during later intervals.

Panel B presents mean response rates for each 60 -sec period for each $S$ during the final 10 CS-US sessions. Pre-CS responding was not systematically different from that observed during the first $10 \mathrm{CS}$-US sessions (Panel B compared to Panel A). The onset of CS resulted in a temporary increase in responding for all Ss, followed by reduced responding; toward the end of the CS period, responding again increased. The U-shaped function during CS observed in Panel A is quite pronounced in Panel B, as is the enhanced responding during the post-CS periods.

Panel C presents the mean response rates of each $S$ during the final eight sessions, during which CS was presented alone. Pre-CS response rates under this procedure matched those previously observed. Response rates during CS were greater than during the pre-CS period and during the CS
Table 1

The Mean Shock Rates for Each S During Each Experimental Period. See text for details.

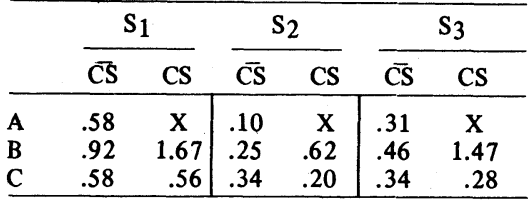

periods shown in Panels $A$ and $B$. The increased responding during post-CS periods shown in Panels A and B was not maintained when CS-alone was presented.

Table 1 presents the mean shock rates for the experimental periods identified in Fig. 1. Row A presents mean shock rates during the final 10 FOA training sessions; Row B presents mean shock rates for all CS-US sessions during signaled (CS) and nonsignaled $(\overline{\mathrm{CS}})$ periods; and Row $\mathrm{C}$ presents mean shock rates during the CS and $\overline{C S}$ periods of the final 5 sessions, during which CS was presented alone.

Shock rates during signaled periods were greater than during nonsignaled periods for all Ss, although the CS-US procedure resulted in greater shock rates as compared to the last FOA training sessions. When CS was presented alone, shock rates during CS approximated those during nonsignaled periods.

\section{DISCUSSION}

The results of this experiment show that when a stimulus pair, CS-US, is presented in competition with a free-operantavoidance schedule (FOA), response rate during the signaled period declines. In addition, responding during the pre-aversive stimulus (CS) shows substantial changes over time: The observed U-shaped response function probably reflects. the fact that after the initial decline in response rate, the rate increased because the animal received some of the avoidable shocks in the latter part of the CS interval. Such differential responding during $\mathrm{CS}$ would not have been observed had a single response count been obtained, as is commonly done.

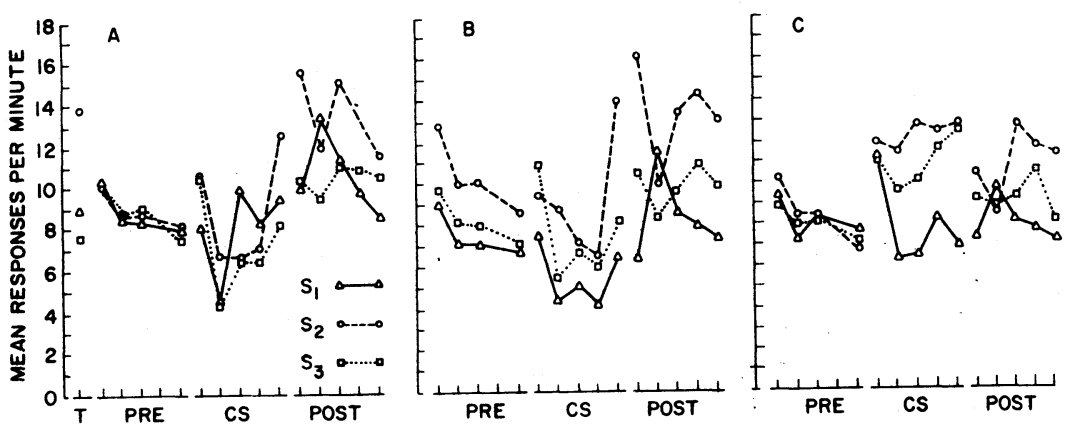

Figure 1

This finding is contrary to the conclusion reached by Rescorla \& Solomon (1967), who claimed that a pre-aversive stimulus enhances anxiety-motivated behavior. The results, furthermore, are at odds with some earlier studies where it was reported that a pre-aversive stimulus enhances avoidance behavior. These studies differ from the present one in several respects: Different species were used as Ss, and different parameter values than those reported in this paper were examined (Kelleher, Riddle, \& Cook, 1963; Waller \& Waller, 1963).

Finally, it should be pointed out that the conclusions of Rescorla \& Solomon (1967) are based on experimental procedures in which the probe operations used to identify the functional properties of CS involved a CS-US extinction procedure, i.e., presenting CS alone (e.g., Rescorla \& LoLordo, 1965). The data shown in Panel C demonstrate that this procedure does not result in enhanced responding during $\mathrm{CS}$, relative to pre-CS response rates. It is, therefore, appropriate to conclude that CS does not have a unitary function-as suggested by Rescorla \& Solomon (1967)-but affects behavior differently depending on whether the stimulus continues to be associated with a US.

Our finding, that CS presented alone results in enhanced responding, raises a fundamental issue: why a stimulus, no longer a signal for US, acquires response-enhancing properties maintained over hundreds of presentations. Additional experiments are in progress to answer this question.

\section{REFERENCES}

HURWITZ, H. M. B., \& BLACK, R. E. Risk taking behavior under conditions of punishment. Paper presented to Southeastern Psychological Association, Roanoke, Virginia, 1968.

KELLEHER, R. F., RIDDLE, W. C., \& COOK, L. Persistent behavior maintained by unavoidable shocks. Journal of the Experimental Analysis of Behavior, 1963, 6, 507-517.

RESCORLA, R. A., \& LoLORDO, V. M. Inhibition of avoidance behavior. Journal of Comparative \& Physiological Psychology, $1965,59,406-412$.

RESCORLA, R. A., \& SOLOMON, R. L. Two process learning theory: Relationships between Pavlovian conditioning and instrumental learning. Psychological Review, 1967, 74, 151-182.

SIDMAN, M. Avoidance conditioning with brief shock and no exteroceptive warning signal. Science, 1953, 118, 157-158.

WALLER, M. B., \& WALLER, D. F. The effects of unavoidable shocks on a multiple schedule having an avoidance component. Journal of the Experimental Analysis of Behavior, 1963, 6, 29-37.

\section{NOTE}

1. This research was supported by NSF Grant GB-8505. 